\title{
EDUCAÇÃO PERMANENTE E O CUIDADO EM SAÚDE: ENSAIO SOBRE O TRABALHO COMO PRODUÇÃO INVENTIVA
}

\author{
PERMANENT EDUCATION AND CARE IN HEALTH: ESSAY ON THE JOB \\ AS PRODUCTION INVENTIVE
}

\section{Janaina Matheus Collar}

Internacionalista. Mestranda no Programa de Pós-Graduação Saúde Coletiva, Universidade Federal do Rio Grande do Sul (PPGCOL/UFRGS). E-mail: janainacollar@gmail.com

\section{João Beccon de Almeida Neto}

Doutorando no Programa de PósGraduação em Bioética e Saúde Coletiva (UFF/UFRJ/UERJ/FIOCRUZ). Professor da Universidade Federal de Juiz de Fora - Faculdade de Direito.

E-mail: jbeccon@gmail.com

\section{Alcindo Antônio Ferla}

Doutor em Educação. Professor Adjunto da Escola de Enfermagem da Universidade Federal do Rio Grande do Sul.

E-mail: ferlaalcindo@gmail.com

\section{Resumo}

Ensaio sobre conexões entre o trabalho e a formação em saúde num plano micropolítico, a partir de perspectivas teóricas que mobilizaram os autores na reflexão sobre a educação permanente e a integralidade em saúde. O estilo ensaístico se compôs de inquietações, conceitos, teorias, experiências, metáforas e análises do contexto atual. $O$ ensaio foi constituído em três movimentos. Um primeiro deles fez aproximações entre a formação profissional e o trabalho em saúde, buscando explicitar uma dimensão técnica (o domínio de certo conjunto de conhecimentos e técnicas) e uma dimensão política (a produção de modos de subjetivação que moldam a relação do sujeito com o trabalho). Um segundo movimento tomou o trabalho em saúde na contemporaneidade como campo de problematizações, desenvolvendo a ideia da potência do conhecimento produzido no/ pelo trabalho como dispositivo para a autonomia do trabalhador no cotidiano. Por fim, o encontro entre educação permanente e trabalho em saúde é dispositivo para refletir sobre a gestão do trabalho, a integralidade e o cuidado inclusivo.

Palavras-chave: Educação Permanente em Saúde; Saúde Coletiva; Ensino das profissões da Saúde; Subjetividades. 
Abstract

Essay about connections between work and health training in micro-political plan, from theoretical perspectives that mobilized the authors reflection on lifelong learning and comprehensiveness in health care. The essay style consisted of concerns, concepts, theories, experiences, metaphors and analyzes the current context. The test consisted of three movements. A first one made links between the vocational training and health work, and endeavors to identify a technical dimension (right domain set of knowledge and skills) and a political dimension (the production of subjectivity in ways that shape the subject's relationship with the job). A second movement took health work nowadays as problematizations field, developing the idea of the power of knowledge produced in / the work as a device for the autonomy of the worker in everyday life. Finally, the meeting between lifelong education and health work is device to reflect on the management of labor, completeness and comprehensive care.

Keywords: Continuing Health Education; Public Health; School of Health Professions; subjectivities

\section{Um ensaio sobre a educação e o trabalho}

Este ensaio nasceu da motivação por pensar conexões entre o trabalho e a formação em saúde num plano micropolítico, a partir de perspectivas teóricas que mobilizaram os autores na reflexão sobre a educação permanente e a integralidade em saúde. Tal qual num jogo de quebra-cabeça, foram inicialmente compartilhadas peças confeccionadas nas diferentes formações e atuação dos autores. O estilo ensaístico se compôs de inquietações, conceitos, teorias, experiências, metáforas e análises do contexto atual. Não perseguimos um objetivo de ineditismo e densidade teórica ampliada, apenas 0 de compartilhar reflexões a partir de conexões teóricas, empíricas e também afetivas que o jogo nos foi oferecendo.

O ensaio foi constituído em três movimentos. Um primeiro deles fez aproximações entre a formação profissional e o trabalho em saúde, buscando explicitar uma dimensão técnica (o domínio de certo conjunto de conhecimentos e técnicas) e uma dimensão política (a produção de modos de subjetivação que moldam a relação do sujeito com o trabalho). A educação permanente em saúde é proposta como brecha no cenário atual, que produz abertura para a organização do trabalho de formas mais potentes para a produção da integralidade. Um segundo movimento tomou o trabalho em saúde na contemporaneidade como campo de problematizações, desenvolvendo a ideia da potência do conhecimento produzido no/pelo trabalho como dispositivo para a autonomia do trabalhador no cotidiano. Por fim, o encontro entre educação permanente e trabalho em saúde é dispositivo para refletir sobre a gestão do trabalho, a integralidade e o cuidado inclusivo. 


\section{Educação permanente para práticas de integralidade: uma brecha à criação nas políticas e práticas contemporâneas}

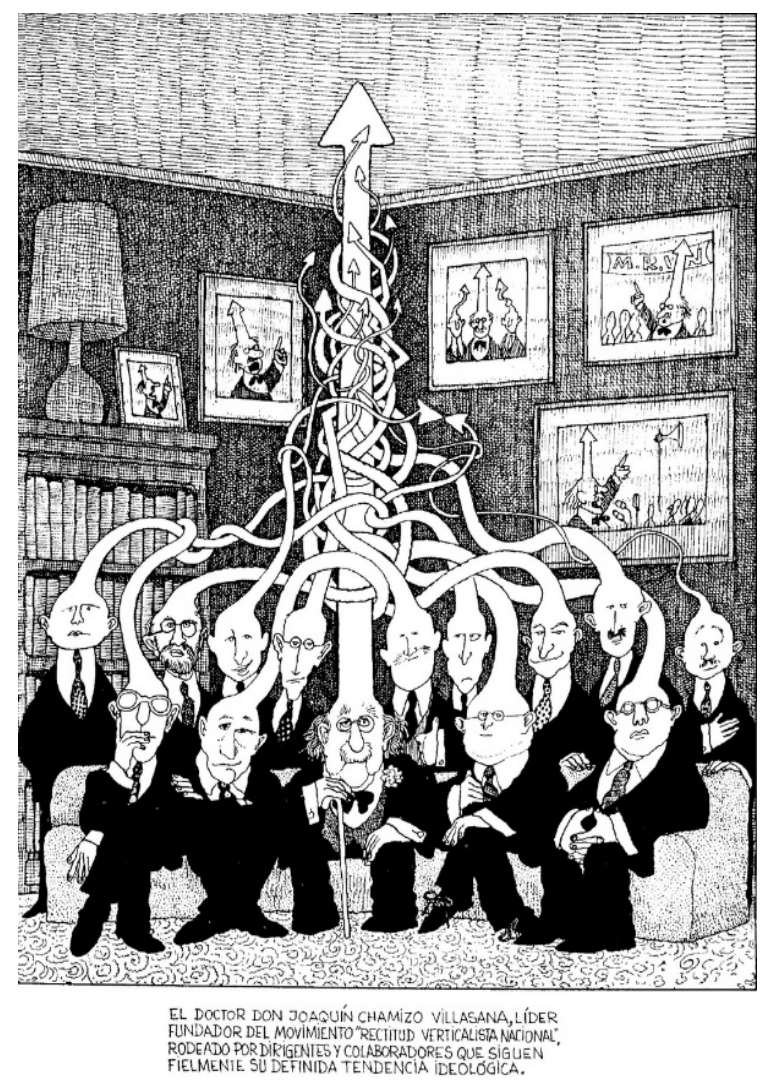

Fonte: Quino. Quinoterapia. São Paulo: Martins fontes, 2004.

Um dos principais objetivos do SUS é a atenção integral à saúde das pessoas e das coletividades, envolvendo o uso de diferentes naturezas de tecnologias como destaca, em diversas produções teóricas sobre a micropolítica do trabalho em saúde, Emerson Merhy (equipamentos tecnológicos, saberes estruturados e tecnologias leves, as quais são a base da gestão do cuidado). Importante, no contexto de um trabalho complexo e com grande densidade tecnológica, reconhecer a autonomia do usuário, porque a oferta de saúde precisa ser resolutiva, mas ao mesmo tempo fazer sentido para o usuário e gerar padrões de liberdade em relação à doença e à dependência dos serviços. Não há cuidado integral se não houver produção de autonomia para o sujeito, já que essa é uma dimensão das necessidades de saúde. ${ }^{1}$

Para a realização efetiva desse trabalho, a análise dos muitos atravessamentos que perpassam trabalhadores e usuários, é imprescindível para se constituir uma rede de cuidados híbrida. No ato de cuidar, a dimensão micropolítica, que mobiliza reações na interação com o outro, toma a cena e produz sentidos diversos para o cuidado. As relações que se estabelecem na cena do cuidado também são atravessadas por normas e protocolos, que normalmente estabelecem molduras fixas e incidem sobre a cultura de saúde das pessoas. Mas, em tempos de fluxos migratórios intensos, os conhecimentos que precisam ser mobilizados para o cuidado requerem a desnaturalização do conceito de "cultura local" para incluir o contato com valores, culturas e produções que auxiliem na resposta ampla ao direito fundamental a vida de todos e todas, de forma integral. Mais do que um problema operacional, a capacidade de deixar a prática tornar-se híbrida de valores e saberes diversificados, potencializa a integralidade pela abertura à alteridade. Para tanto, é necessário pôr o trabalho, a relação com o trabalho e a relação com o outro em análise, buscando quebrar as naturalizações que o conhecimento, a técnica e as normas dos serviços tendem a produzir. $O$ cuidado não será integral se apenas estiver moldado pelo conhecimento biomédico disponível.

É necessário nutrirmos um olhar questionador, pois a ?segurança? dos conceitos naturalizados, duros e lacrados em caixotes, tem efeito de sedação à capacidade de criação, à inovação, ao viver saúde e ao exercício permanente de viver em intensidade e inventar novos modos de andar a vida, que, afinal, são marcadores contemporâneos da saúde. Mais do que a capacidade de mobilizar todos os 
conhecimentos e capacidades profissionais decorrentes das técnicas e normas, falamos aqui de uma competência em Educação Permanente em Saúde, como filtro e como dispositivo para mobilizar conhecimentos úteis e oportunos, localizados na cena do cuidado, que fazem avançar a integralidade no cotidiano. Através deste movimento, acreditamos que se forme e consolide em cada um de nós escuta e gestão do cuidado, mobilizado o quadrilátero da formação ${ }^{2}$, estabelecendo assim, uma visão singular de todos e de cada indivíduo no momento em que se expressa o encontro no sistema de saúde. Por isso que atenção (oferta de saúde) está sempre associado à gestão (como se organiza a política), à participação (a expressão do singular) e a formação (há aprendizagem que precisa ser feita o tempo todo), "constituem a prática da qualidade da formação para o desenvolvimento tecnoprofissional, o ordenamento da rede de atenção e a alteridade com os usuários." ${ }^{2}$ Conhecimentos e práticas precisam ter movimento no interior dos serviços, para produzir vetores de força para a integralidade. Ao mesmo tempo em que a formação profissional distribui identidades para o trabalho, precisamos produzir quebras nessas identidades para um cuidado integral, que busque responder às necessidades de saúde de pessoas e coletividades, que são sempre diversas. Esses movimentos, a conexão dos saberes com o cotidiano do trabalho e a aprendizagem constante e significada pela capacidade de embasar ações profissionais compõem a Educação Permanente em Saúde (EPS).

Desenvolver na rede pública de saúde, interconexões de ensino-aprendizagem no exercício do trabalho está intimamente ligado ao conceito e formação da EPS e, nesse caso, também é o dispositivo que permite avançar na mobilização de saberes e tecnologias adequadas ao cuidado integral. Este movimento não se propõe à formação longitudinal de carreiras, mas no estreitamento da relação entre "(...) formação, gestão, atenção e participação nesta área específica de saberes e de práticas, mediante as intercessões promovidas pela educação na saúde (a educação intercede pela saúde, ofertando suas tecnologias construtivistas e de ensinoaprendizagem)." ${ }^{\prime: 976}$ A EPS, como política púbica, tem tomado forma nas práticas de atenção em saúde desde 2003, com a formação de política nacional específica aprovada pelo Conselho Nacional de Saúde, cujo termo, destarte, era inexistente até então. ${ }^{3}$ Essa política se espalha também como prática de ensino-aprendizagem e como gestão da aprendizagem no cotidiano dos sistemas e serviços de saúde. É a aprendizagem colada ao cotidiano do trabalho, mobilizada pelos problemas e situações do mundo do trabalho, e que constrói redes de saber para a ação a partir do cotidiano.

Pela agenda de formação da EPS, mais do que educação profissional, a aprendizagem atua no desenvolvimento do trabalho no cotidiano dos sistemas e serviços, mobilizando aprendizagens que colocam em contato o trabalho e a produção de conhecimentos. ${ }^{4}$ A proposta da EPS é "tomar o cotidiano como lugar aberto à revisão permanente e gerar o desconforto com os lugares 'como estão/como são'."' 5:166 Por isso, a EPS, como modo de aprender, se produz no cotidiano do trabalho, no "entre" dos diferentes papéis que são desempenhados na cena do cuidado, e, como política, se forma no entre setores, no entre ministérios (Saúde e Educação). Tudo isso com o intuito de fomentar, trazer transformações do trabalho, dando espaço ao pensamento reflexivo, crítico e criativo, para deixar de lado as reproduções da cultura institucionalizada no seio dos serviços e para quebrar o elo inflexível entre conhecimento especializado como ferramenta que produz racionalidade para 
o trabalho. O Ministério da Saúde, nesse sentido, considerou como caminho para formação e promoção da EPS a indução de projetos de mudança na educação técnica, na graduação, nas especializações em serviço, nas residências médicas ou outras estratégias de pós-graduação; desenvolvimento dos trabalhadores e dos gestores de saúde; envolvimento com o movimento estudantil da saúde; produção de conhecimento para a mudança das práticas de saúde e de formação, bem como a educação popular para a gestão social das políticas públicas de saúde.

A escolha da Educação Permanente em Saúde como ato político de defesa do trabalho no SUS decorreu do desafio para que o setor da saúde correspondesse às necessidades da população, conquistasse a adesão dos trabalhadores, constituísse processos vivos de gestão participativa e transformadora e seduzisse docentes, estudantes e pesquisadores à mais vigorosa implementação do SUS. 3:979

É uma proposta que não só coloca a educação no seio da agenda e das políticas públicas, mas que vem ao encontro da ruptura de uma formação profissional assistencialista e centrada no conhecimento biomédico, cujo espaço de subjetividades procura-se manter nulo, tanto no âmbito dos saberes e práticas, quanto no cuidado ao usuário. O profissional como detentor do saber que domina a vigência das práticas, produzido pela incorporação dos conhecimentos e técnicas validados pela ciência vigente, ainda é o padrão da formação profissional em saúde desde as origens, no final da idade média. A formação profissional se expressa de forma mais fiel na absorção do conhecimento disponível e o desenvolvimento da habilidade de tornar-se sujeito desse conhecimento e das técnicas que ele produz. É sabido que esse discurso anulou a escuta, ao menos a escuta de intensidade, pois o importante era o diagnóstico da doença e prescrição do tratamento, independente da singularidade que congrega a trajetória de cada usuário e das sensações que o encontro do usuário com o serviço produz. Para isso, não é necessária essa dimensão da escuta, apenas a identificação de sinais e sintomas que podem advir da objetivação da fala do outro. O hospital, para dar um exemplo, quando deixa de ser o local para assistir à morte e passa a ser o local de tratamento das doenças, não visou o cuidado ao doente ao tratar a doença, mas evitar que a doença fosse potencializada a partir do próprio hospital e que as doenças não se espalhassem pela cidade. ${ }^{6}$ Há um duplo fluxo disciplinar nessa origem: a disciplina da organização do hospital e suas práticas e a disciplina de organização da cidade e do estado civil. Em ambas, o predomínio da ordem disciplinar sobre a vida, de uma biopolítica que se exerce sobre todas as vidas. $^{7}$

Essa forma de interpretar a relação entre saúde e doença passa a sofrer críticas na contemporaneidade. Contudo, inolvidável que os discursos cientificistas reforçavam a armadura biomédica de negar a escuta. Nesse sentido, não há como negar a própria influência desse discurso na gestão, que se entregava ao conhecimento provado/ditado pelo método e aplicado a partir de critério de utilidade (não é à toa o quanto a ética utilitarista se destacou no período, sendo uma das bases da própria formação das nossas instituições disciplinares ou de biopolítica). ${ }^{8}$ São exemplos desse cenário, as influências aos currículos médicos do Relatório Flexner (1910), a Revolta da Vacina no Rio de Janeiro (1904), a promoção em saúde através de outras práticas, interpretadas em alguns momentos como acientíficas, como Homeopatia $^{9}$ e o uso de ervas medicinais, que ainda encontramos na literatura como sendo cuidados ou medicinas alternativos/ 
as ou complementares. Saberes tradicionais, validados ao longo da história pelo uso em diferentes culturas e grupos, deslocamse para o limite do que pode ter vigência para ordenar as práticas de cuidado por meio do rótulo de "alternativo" ou mesmo "complementar".

Portanto, a inscrição de sentidos no trabalho não se constitui em ato, mas é previamente pensada e instituída a partir da ciência vigente, fazendo com que houvesse como que uma objetividade anterior ao momento do cuidado, definida a partir da ciência e da técnica biomédica. E essa objetividade constitui os discursos que são considerados legítimos no sistema de saúde como um todo. Isso fez crescer o abismo entre formação, gestão, profissionais e usuário. Não obstante, a integralidade e a intersetorialidade ainda têm enorme dificuldade de sair do papel. Ceccim, em 2005 , chamava a atenção para determinados aspectos que ilustram essa dificuldade:

Os gestores do SUS que querem transformar as práticas, reclamam que os profissionais vêm para o SUS com formação inadequada, que os estudantes não são expostos às melhores aprendizagens $e$ que as universidades não têm compromisso com o SUS.

Osdocentese asescolas que querem mudar a formação reclamam que as unidades de saúde não praticam a integralidade, não trabalham com equipes multiprofissionais, são difíceis campos de prática e que os gestores são hostis em produção de pactos de reciprocidade..$^{3: 983-984}$

Estas ainda são questões importantes, fazendo com que seja importante cada vez mais se pensar num ambiente menos fixo, mas reflexivo. Não exatamente moldado por experimentalismos empiristas, mas por exercícios de reflexão e análise, onde problemas e soluções tenham conexões com o cotidiano vivido. Porém, como realizar a EPS em nossa sociedade ainda muito imediatista e individualista?

\section{Identidades, individualismos e excessos: quando tudo parece demasiado para a aprendizagem}

Sem nos atermos aos embalos de conceitos de qual época vivemos e seus desdobramentos, como o pós-modernismo, modernismo tardio, contemporâneo, ... queremos refletir aqui sobre o hoje, dentro do espaço onde estamos inseridos, e o que enxergamos como nosso território, não como proprietários de um lugar, mas como viventes em um espaço que é individualizado por escolha ideológica, ética e moral, e com este se afeta/desassossega. A reflexão sobre o trabalho, aqui, pretende centrar-se numa perspectiva de certos atravessamentos culturais do nosso tempo sobre os sujeitos do trabalho em saúde e do cuidado. Os tempos atuais produzem vetores de força sobre as pessoas sobre os quais nos parece necessário refletir um pouco mais para seguir pensando a relação entre trabalho em saúde e formação.

Falamos em liquidez dos sentimentos relacionais, uma vez que a vida corre literalmente de forma desordenada e rápida. O tempo do pensamento reflexivo parece inexistir. Não obstante, temos a tendência de confundir nossa racionalidade com critérios de utilidade, que associados à celeridade, nos forçam a uma plasticidade da vida e das relações. As relações não necessitam de durabilidade, mas de intensibilidade e de rapidez. O soma' tem

' O soma é a droga criada por Aldous Huxley em sua obra "Admirável Mundo Novo" (1932) em que seus personagens consumiam a fim de que eles nunca ficassem tristes, mas sim se mantivessem felizes. Cabe destacar que a obra de Huxley traz como cenário um mundo futurista, onde a humanidade se estabelece da forma mais racional possível, onde 
diversas roupagens em nosso admirável mundo, cujo próprio conceito de novo é reinventado constantemente. Somos seres portadores de vontades imediatas. Somos seres desejantes de prazer imediato, como se equivalesse à vida em intensidade. Diversas novas drogas são disponibilizadas diariamente, justamente para perseguir essa condição. Mas é paradoxal como facilmente culpabilizamos o fabricante, ao invés de repensamos sobre nossas próprias vontades. A construção do papel de cidadão parece se esgotar na condição de consumidor de produtos e serviços; assim como o sujeito saudável parece requerer apenas o consumo de um certo conjunto de drogas e de procedimentos biomédicos e de adestramento físico.

Vivemos uma sociedade muito individualista, cujo sintoma mais marcante é o centramento na vontade imediata e a culpabilização do outro por frustrações na satisfação dessa vontade. Como já afirmamos, a reflexão não passa de algo distante, em muitas situações do cotidiano. Thomas Bernhard em seu conto o "O imitador de vozes", narra uma cena onde um formidável imitador de vozes, após sua apresentação e atender inúmeros pedidos de imitações, não consegue atender ao simples pedido de que realizasse a imitação de sua própria voz."

inexiste casamento, relacionamentos amorosos, sendo incentivado a busca pelo prazer do sexo e pelo uso de drogas. Os seres humanos eram subdividos em castas conforme a sua função social e reproduzidos por meio de incubadoras. ${ }^{10}$

" "Convidado de ontem à noite da Sociedade Cirúrgica, o imitador de vozes, depois de se apresentar no Palais Pallavicini a convite da própria Sociedade Cirúrgica, já havia concordado em se juntar a nós na Kahlenberg para, também ali, na colina onde mantemos uma casa sempre aberta a todas as artes, apresentar seu número, naturalmente não sem o pagamento de cachê. Entusiasmados com o espetáculo a que tínhamos assistido no Palais Pallavicini, pedimos ao imitador de vozes, natural de Oxford, na Inglaterra, mas que frequentou escola em Landshut e exerceu de início a profissão de armeiro em Berchtesgaden, que, na Kahlenberg, não
Podemos utilizar essa situação para ilustrar um pouco da reflexão que propomos aqui, que coloca a capacidade de análise de si e das relações com o entorno como dispositivo de aprendizagem permanente. Assim como o imitador de vozes em seu número, internalizamos e reproduzimos diversas práticas visíveis e audíveis ao nosso redor. Desenvolvemos, ao longo da vida, a capacidade de lapidar nosso personagem (o que desempenhamos no cotidiano, como profissionais, usuários, cidadãos) a partir de um conjunto de valores que são vigentes e que definem o modo considerado adequado de existir e andar a vida. Aqui o desafio parece ser outro, o de criar personagens que sejam capazes de superar os obstáculos do cotidiano e produzir autonomia, saúde, aprendizagens. Não há aprendizagem se não houver transformação e, assim, o aprender ventríloquo das vozes alheias não tem outro efeito que não de reforçar as identidades e as práticas vigentes. "Outras vozes", nesse caso, não compõem alteridade, mas apenas ventriloquia. A falta desse exercício reflexivo radical nos remete a uma exacerbação do movimento individualista, que também constitui alienação no andar a vida.

Inserimos aqui uma metáfora, o amanhecer de primavera, para falar de algo que sempre nos é convidativo, mas que produz efeitos nos modos de andar a vida, inclusive no trabalho. Num amanhecer de primavera, temos a sensação de que tudo está em seu devido lugar e que, portanto, é necessário reservar apenas um espaço exíguo a questionamentos. $O$ excesso de

se repetisse, mas apresentasse algo inteiramente diverso do mostrado na Sociedade Cirúrgica, ou seja, que imitasse na Kahlenberg vozes inteiramente diferentes daquelas imitadas no Palais Pallavicini, o que ele prometeu fazer. $\mathrm{E}$ de fato o imitador de vozes imitou na Kahlenberg vozes inteiramente diferentes daquelas apresentadas na Sociedade Cirúrgica, algumas mais, outras menos famosas. Pudemos inclusive fazer pedidos, aos quais o imitador de vozes atendeu com a maior solicitude. Quando, porém, no final, sugerimos que imitasse sua própria voz, ele disse que aquilo não sabia fazer."11:capa 
cores é quase orgástico, ele seda qualquer incômodo. É um dia que, para além da contemplação, representa a própria imagem do prazer imediato. É nesse contexto que colocamos na discussão a micropolítica do trabalho, em especial de como nos relacionamos com o processo de produção de cuidado.

Invariavelmente observamos que a produção do cuidado é capturada por um conteúdo tecnológico muito específico, principalmente por equipamentos, conhecimentos e técnicas mais programáticos. Há um grande desenvolvimento científico e tecnológico na saúde e isso se coloca, diante dos desafios do cuidado, como um jardim bem cuidado, diante do qual só nos resta a imobilidade. Quando analisamos o trabalho na saúde, geralmente identificamos a vigência dos protocolos de atendimento, o volume de demanda da equipe, bem como a própria equipe que reproduz uma forma preestabelecida de atendimento, procurando evitar o surgimento do novo; não há outros possíveis na cena tomada pelas ofertas tecnológicas da biomedicina. Essa cultura institucionalizada, com o tempo, é internalizada e reproduzida pelo novo membro da equipe. Assim, somado com o tempo que é algo incalculável, não há momento de reflexão ou de quanto cada um repensa sua prática. Há, mesmo, uma espécie de abdicação da necessidade de liberdade para agir por fora das regras e das normas. Com tanta abundância, parece que qualquer liberdade é excessivamente perigosa e, mais além, desnecessária.

O conceito de liberdade para Spinoza ${ }^{12}$ equivale a realizar aquilo que vem de você mesmo. Aquilo que está em você mesmo. Realizar sua própria natureza. Portanto, realizar algo em liberdade, seria não se deixar vincular a coisas externas, no sentido de se deixar tomar por essas coisas. Nós estamos sempre em luta, seja da cultura, sejam valores religiosos e normas institucionais. Para Spinoza, a natureza não é algo inerte. Assim, como nossos desejos são produtos de nossas afecções, a liberdade não existe em sua completude, mas em certos graus de liberdade em consonância com certos graus de captura.

Nesse sentido, nossos desejos não são exclusivamente produtos de nossa liberdade, mas também de atravessamentos que nos afetam. Da mesma forma, nossos direitos não são bens de uso, de frutos ou de abuso. "Os direitos humanos estão ligados a uma ideia de liberdade que inclui, também, o dever de lutar por ela.."13:165 Isso significa que são formados pelo diálogo, pelas lutas, vivências em conflitos, aprender com as dificuldades. Portanto, fazem parte do entorno de cada pessoa. Nesse sentido, fica sedutoramente fácil entendermos de forma individual o sentido de luta, mas quando pensamos no desejo do outro, as dificuldades aumentam, pois o outro é um estranho e que deve se cuidar por si. Mas como não faz sentido existir direito na ilha de Robson Crusué, não há o eu sem o outro e a formação de desejos e sociedades. A alteridade constitui a condição humana, considerando que não é uma identidade fixa, mas um processo que se transforma pela aprendizagem em contato com outras pessoas e coisas.

Spinoza ${ }^{12}$ elenca três proposições de conhecimento: 1a) impróprio, produzido a partir exclusivamente de afetos, na sua relação com os outros; uma 2a) produto da racionalidade científica, que não pode por si só se completar, mas geram conhecimentos verdadeiros. E uma 3ạ) ciência intuitiva, em que é criado conhecimento a partir das forças imanentes à própria pessoa e as percepções sensíveis. ${ }^{12}$ Essas ideias nos ajudam a refletir um pouco mais sobre a organização do trabalho.

De certa forma o território onde se realiza o trabalho é interpretado como um 
ambiente racionalizado e que necessita ser assim para que seja mantida uma certa ordem. Ordem, por certo, não é igual a estagnação de movimentos, a uma tensão entre fixos e fluxos. O conhecimento é fruto da capacidade de sistematização, sendo o pesquisador um observador/analisador. Assim, os processos de produção não reconhecem a experiência, olvidandose, por exemplo, que o pesquisador é implicado pelo tema, envolvendo-se com o próprio objeto. Há uma relação de cognição e afeição. Essa forma de produção de conhecimento não deve ser ignorada. A produção de conhecimentos no espaço do trabalho precisa reconhecer as diferentes motivações que o produzem; não há somente um conhecimento exterior, mas modos como ele se relaciona com o trabalho real e modalidades de conhecimento intuitivo e vivencial que pertencem aos sujeitos do trabalho e, no caso do cuidado, aos usuários.

Ao encontro disso, Hardt ${ }^{15}$ comenta sobre a formação do trabalho imaterial a partir da pós-modernidade. O quanto ele pode ser libertador, mas ao mesmo tempo pode servir a lógica vigente. Como uma das formas de trabalho imaterial, o trabalho afetivo ao produzir cuidado, pode estar, em sua produção, servindo-se de lógicas capturadas pela vigência, reproduzidas pelo coletivo, sem espaço à liberdade ou à autonomia. É inegável que o trabalho afetivo tenha potencialidade libertadora, mas para isso, necessita de que o trabalhador tenha espaço para compreender sua relação com o próprio trabalho e repensar sua forma de produção. ${ }^{15}$ Essa liberdade que o trabalhador da saúde tem em sua produção de cuidado pode ser usada tanto para a reafirmação do modelo biomédico, quanto pela possibilidade de uma formação criativa desse trabalho. Veja-se que toda a normativa corporativa de ordenamento do trabalho das entidades profissionais na saúde, por exemplo, usa a expressão "autonomia" não para falar de liberdade de escolhas do profissional para organizar o seu trabalho, mas justamente da necessidade que o mesmo se deixe tomar pela lógica com que o conhecimento científico e tecnológico do seu núcleo profissional configura esse trabalho. Ou mesmo os processos de formação profissional, onde se avalia o desempenho do estudante não pela sua capacidade de mobilizar conhecimentos para resolver os problemas do cotidiano, mas do volume de conhecimentos que o mesmo adquiriu no percurso da formação.

Para avançar na capacidade de cuidado como liberdade de mobilizar recursos cognitivos, simbólicos, tecnológicos e relacionais para ampliar a autonomia dos sujeitos que buscam cuidado, parece necessário o desenvolvimento de capacidades profissionais de interagir com os desafios do cotidiano e produzir subjetividades marcadas pela autonomia de cada trabalhador comprometido eticamente com o cuidado do outro. Nesse processo, mobilizar técnicas e conhecimentos prévios e uma das habilidades necessárias, mas o desenvolvimento do trabalho estará na capacidade de interagir com o contexto, de mobilizar redes de saberes locais; enfim, de produzir educação permanente em saúde. ${ }^{16} \mathrm{O}$ trabalho não é apenas aplicar conhecimentos; também é mobilizar o reconhecimento de saberes e a produção de novos conhecimentos. 
Para concluir: pensar o trabalho como uma manhã chuvosa com vento

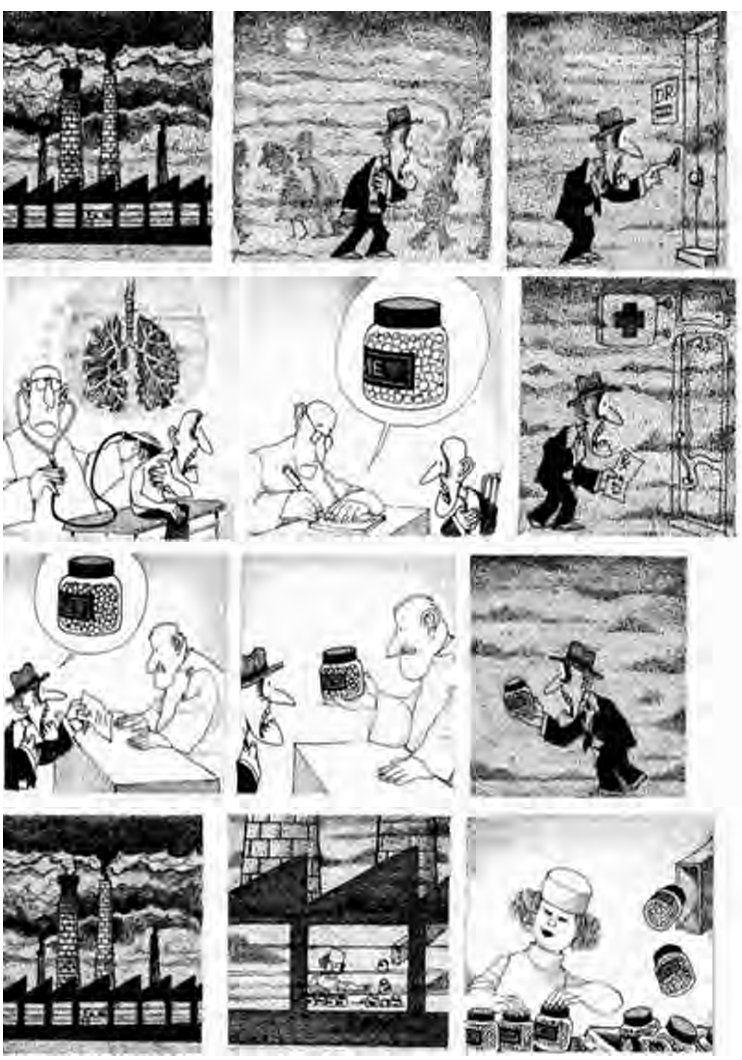

Fonte: Quino. Quinoterapia. São Paulo: Martins fontes, 2004.

Considerar o trabalho como produtor de conhecimentos, traz à cena a educação permanente em saúde, que no caso do sistema de saúde brasileiro, é uma política. A EPS propõe um olhar hibrido sobre o cotidiano do trabalho, movimentado por se permitir questionar, se constituir como integrante do território, e assim fomentar a alteridade de cada um daqueles que compartilhamos nossas vivências.

Como num amanhecer chuvoso e agitado pelo vento, a EPS, deve mobilizar conceitos, campos de vivências e práticas voltadas para o cotidiano. Nos aproximamos aqui do conceito de práxis para seguir na reflexão sobre a relação formação e trabalho: "A teoria sem a prática vira 'verbalismo', assim como a prática sem teoria, vira ativismo. No entanto, quando se une a prática com a teoria tem-se a práxis, a ação criadora e modificadora da realidade."17:23 Onde não há o estar só (nem no lugar do saber, nem no lugar do poder), mas o compartilhar de experiências de "lugares". Vale aqui o destaque para o atravessamento da teoria e da prática, mas vale também o movimento que muda teoria e prática. Essa dupla perspectiva nos permite retomar a ideia da integralidade para pensar nos desafios do encontro educação e trabalho na saúde.

Segundo Cortella a "integralidade é um fundamento ético que deve ser internalizado e praticado - concepção e prática"18:26. É preciso que a prática e a teoria andem juntas. ${ }^{17}$ Inclusive por se tratar, em ambos os casos, de práticas: práticas de trabalho e práticas de saber. Entretanto, no cotidiano do trabalho, muitas vezes é difícil perceber que há muito a ser feito. Sobrecarga de trabalho, pressão por respostas rápidas, diferentes graus de envolvimento dos trabalhadores com 0 trabalho ...: há muitas razões para deixar o trabalho ser guiado por forças externas, mas essas mesmas razões podem, justamente, descrever a importância da reflexão e da análise (também da auto-análise) sobre o cotidiano do trabalho. É preciso pôr o trabalho em movimento: deixa-lo atravessar-se pelo híbrido produzido no encontro teoria e prática e mobilizá-lo pelo desafio da integralidade. As iniciativas de educação permanente no nosso cotidiano têm desafios importantes, considerando essas conexões.

Para isso é necessário pôr em análise os modos de gestão do trabalho e sua influência no cotidiano. A educação permanente pode mobilizar formas coletivas de organização do trabalho, tornando-o também ação comunicativa. A ação comunicativa ${ }^{19}$ pressupõe que todos os interessados possam participar do discurso, 
que todos tenham oportunidades idênticas para argumentar, refutar ou interpretar. Supõe ainda que só serão admitidos aqueles participantes que se disponham a agir de acordo com normas que lhes pareçam justificáveis. Compreender o trabalho também como ação comunicativa provoca a participação de cada um, mas também o reconhecimento do espaço coletivo como espaço compartilhado de poder para a gestão do trabalho. Há necessidade de produção de alteridade para que isso seja possível.

Outro grande desafio para o trabalho mobilizado pela integralidade é a inclusão de todos e todas que precisam de cuidado. O desafio da prática do cuidado está em cuidar da vida de todos e todas, pois todas as vidas valem a pena. ${ }^{20}$ As sociedades parecem ter naturalizado uma hierarquia de valor para as vidas, separadas por gênero, por raça, por etnia, por profissão, pela renda, pelo padrão de consumo, por estilos de vida, por diagnósticos ... A análise do trabalho requer uma perspectiva ética sobre quais ofertas estão sendo feitas para cada pessoa e coletivo, já que o trabalho é vivo e construído em ato, portanto sujeito a atravessamentos que podem torna-lo não apenas aprisionado pela impessoalidade da técnica, mas também por valores que não respondem à construção ética em que está inserido. $O$ trabalho em saúde precisa ter um efeito pedagógico de inclusão e de valorização da vida, principalmente em tempos de exclusão e violência.

Merhy ${ }^{21}$ descreve que a diferença do outro na prática do cuidado enriquece o trabalho, mas que, infelizmente, na nossa sociedade a diferença é vista de forma ruim e perigosa. Independente da forma com que determinados indivíduos são rotulados, como diferentes, anormais ou anormais do desejo, muitas vezes este indivíduo tem práticas desejastes que a sociedade rejeita e criminaliza. Esta segregação faz com que a prática do cuidado se torne punitiva, que coiba todos aqueles que apostam em outras práticas do viver, sendo necessário o encontro onde se possa constituir um novo sentido para a vida deste e também para o trabalhado em saúde. Muitos profissionais praticam o cuidado através de ações punitivas, exercendo ações como a internação compulsória, a violência obstétrica, entre outras situações, não existindo a prática do dialogo no processo do cuidado para outros sentidos da vida. ${ }^{21}$

Atravessar o trabalho com práticas de educação permanente significa assumir o compromisso de reinventar o trabalho para que possa produzir integralidade. Pensamos aqui a integralidade como obra de arte, singular e resultado do trabalho. O trabalhador, nesse caso, precisa tornarse artista. Um artista que se constitua em movimento.

\section{Referências}

${ }^{1}$. Cecílio LCO, Matsumoto NF. Uma taxonomia operacional de necessidades de saúde. In: Pinheiro R, Ferla AA, Mattos RA (Orgs.). Gestão em redes: tecendo os fios da integralidade em saúde. Rio de Janeiro/Caxias do Sul: CEPESC - IMS/UERJ - EDUCS, 2006, p.37-50.

2. Ceccim RB, Feuerwerker LCM. O Quadrilátero da Formação para a Área da Saúde: Ensino, Gestão, Atenção e Controle Social. PHYSIS: Rev. Saúde Coletiva, Rio de Janeiro, 2004; 14(1): 41-65.

3. Ceccim RB. Educação Permanente em Saúde: descentralização e disseminação de capacidade pedagógica na saúde. Ciência \& Saúde Coletiva, 2005; 10(4):975-986. 


\section{Artigo Original}

4. Ceccim RB, Ferla AA. Educação e saúde: ensino e cidadania como travessia de fronteiras. Trab. Educ. Saúde, nov.2008/fev.2009; 6(3):443-456.

5. Ceccim RB. Educação Permanente em Saúde: desafio ambicioso e necessário. Interface Comunicação, Saúde, Educação, 2005; 9(16): 161-168.

${ }^{6}$. Foucault M. O nascimento do hospital. In.: Foucault M. Microfísica do poder. Tradução e organização de Roberto Machado, 26ed.. Rio de Janeiro: Graal, 1979, p. 99-111.

7. Ferla AA. Clínica em movimento: cartografia do cuidado em saúde. Caxias do Sul: EDUCS, 2007.

${ }^{8}$. Foucault M. Vigiar e Punir. Rio de Janeiro: Vozes, 2008.

9. Luz MT. A arte de curar versus a ciência das doenças: história social da homeopatia no Brasil. Porto Alegre: Rede UNIDA, 2014. 2ed.

${ }^{10}$. Huxley A. Admirável mundo novo. Rio de Janeiro: Biblioteca Azul, 2014.

11. Bernhard T. O imitador de vozes. São Paulo: Companhia das Letras, 2009.

12. Spinoza B. Ética. Belo Horizonte: Autêntica, 2008.

13. Ribeiro JR. Entrevista. Interface, Comunicação, Saúde, Educação. 2003; 7(12):149-166.

${ }^{14}$. Franco TB. A ética em pesquisa e a estética do conhecimento. Revista Brasileira de Sociologia, 2015; 3(5): 203-213.

15. Hardt M. O trabalho afetivo. In: Lancetti A. (Orgs.) O reencantamento do concreto. São Paulo: Hucitec/Educ, 2003, p.144-157.

${ }^{16}$. Franco TB, Merhy EE. Trabalho, produção do cuidado e subjetividade em saúde: Textos Reunidos. São Paulo: Hucitec, 2013.

${ }^{17}$. Freire P. Pedagogia do oprimido. Rio de Janeiro: Paz e Terra, 1970.

${ }^{18}$. Cortella MS. Educação, convivência e Ética - Audácia e Esperança. São Paulo: Cortez, 2015.

19. Habsbawn EJ. Era dos Extremos: Breve século XX. São Paulo: Companhia das Letras, 1995.

20. Merhy EE. Saúde: a cartografia do Trabalho Vivo. São Paulo: Hucitec, 2002.

21. Merhy EE. Entrevista à Rede UNIDA, 2011. Disponível em: <http://www.youtube.com/ watch?v=PaOHadRt5ns>. Acesso em: 26 jun 2014. 